\author{
В. А. Ксенофонтов \\ Военная академия Республики Беларусь
}

\title{
ВОЕННЫЙ КОНФЛИКТ: ТИПОЛОГИЯ И ПРИНЦИПЫ ВЕДЕНИЯ
}

Проблемы военного строительства требуют понимания типов перспективных военных конфликтов, принципов их ведения, так как влияют на идеологию обеспечения военной безопасности. Рассмотрена типология военных конфликтов по критерию применяемых сил сторон (И. М. Попов, М. М. Хамзатов). Участники военного конфликта могут быть двух типов: регулярные, иррегулярные. В зависимости от их состава у сторон военные конфликты классифицируются: традиционная (регулярная) война; усмирительная война; повстанческая война; бандитская война. Продемонстрировано отличие между симметричными и асимметричными военными конфликтами. Рассмотрена западная концепция войны четвертого поколения. Обращено внимание на теорию «мятежевойны» Е. Месснера. Раскрыты особенности войны четвертого поколения, в которой основное поле битвы - национальное сознание и национальная культура. Утверждается, что военные конфликты будут носить сложный регулярно-иррегулярный характер. Показан гибридный военный конфликт. Делается вывод, что характерной особенностью современных военных конфликтов остается комбинированная природа противоборства. Западные теоретики не выделяют четкой границы между войной и миром. Понимание философии борьбы (войны) - методологическая основа обеспечения национальной безопасности.

Ключевые слова: национальная безопасность, военный конфликт, участники военного конфликта, регулярный и иррегулярный характер, гибридный конфликт, философия войны.

Для цитирования: Ксенофонтов В. А. Военный конфликт: типология и принципы ведения // Труды БГТУ. Сер. 6, История, философия. 2021. № 1 (245). С. 161-165.

\section{A. Ksenofontov \\ Military Academy of the Republic of Belarus}

\section{MILITARY CONFLICT: TYPOLOGY AND PRINCIPLES OF CONDUCTING}

Problems of military construction require understanding of types of prospective military conflicts, the principles of their conduct, as they affect the ideology of ensuring military security. Typology of military conflicts according to the criterion of the forces used by the parties is considered (I. M. Popov, M. M. Khamzatov). Participants in a military conflict can be of two types: regular and irregular. Depending on their composition, conflicts are classified as: traditional (regular) war; pacifying war; rebel war; bandit war. The difference between symmetric and asymmetric military conflicts is demonstrated. The western concept of the fourth generation of war is considered. Attention is drawn to the theory of "mutiny" by E. Messner. The features of the fourth generation of war, in which the main field of war is national consciousness and national culture, are revealed. It is argued that military conflicts will have a complex regular-irregular nature. A hybrid military conflict is shown. It is concluded that the combined nature of confrontation remains a characteristic feature of modern military conflicts. Western theorists do not distinguish a clear boundary between war and peace. The understanding of the philosophy of struggle (war) is a methodological basis of ensuring national security.

Key words: national security, military conflict, participants of military conflict, regular and irregular character, hybrid conflict, philosophy of war.

For citation: Ksenofontov V. A. Military conflict: typology and principles of conducting. Proceedings of BSTU, issue 6, History, Philosophy, 2021, no. 1 (245), pp. 161-165 (In Russian).

Введение. Прежде чем совершенствовать вопросы военного строительства и формирования военной сферы национальной безопасности, следует системно разобраться с основными принципами и технологиями военного насилия, так как облик современной (перспективной) войны определяет требования к военной подсистеме национальной безопасности, к гражданско-военным отношениям, сфере культуры и образования (гражданского и военного) [1]. Поэтому целью статьи является - определение основных типов военного конфликта и принципов их ведения, а также определение теоретических и практических шагов в интересах обеспечения национальной безопасности.

Основная часть. Под военным конфликтом будем понимать «форму разрешения противоречий в межгосударственных или внутригосударственных 
отношениях с применением военной силы (средств вооруженной борьбы) противостоящими сторонами: войны различных масштабов, международные и внутренние вооруженные конфликты, а также другие формы применения военной силы» [2, ст. 4].

Рассмотрим типологию военных конфликтов, предложенную российскими военными аналитиками И. М. Поповым и М. М. Хамзатовым [3, с. 283].

В современном военном конфликте помимо регулярных ВС государства могут принимать участие и различные полувоенные, военизированные международные, государственные, квазигосударственные, негосударственные и нелигитимные (криминальные, бандитские) формирования и структуры [3, с. 284].

В целом, все действующие силы военного конфликта могут быть сведены к двум типам: регулярным силам и иррегулярным формированиям.

Регулярные силы представлены, прежде всего, ВС государства, являющегося легитимным субъектом военного конфликта.

Иррегулярные формирования представляют собой различные военизированные структуры, формируемые, как правило, негосударственными акторами, а также в определенных условиях и государством для обеспечения своих интересов.

Как правило, иррегулярные формирования игнорируют законы и обычаи войны, ориентируясь на ведение «войны без правил».

Участники гипотетического военного конфликта в зависимости от поставленных целей и условий обстановки могут применять имеющиеся у них в наличии регулярные силы и иррегулярные формирования в том или ином соотношении. На основании этого формируется четыре типа военных конфликтов, которые условно могут быть представлены в формате матрицы.

Весь спектр возможных вариантов военных конфликтов при столкновении двух сторон сводится к четырем основным моделям, которые условно назвали:

1) «традиционная (регулярная) война». Регулярные ВС против регулярных ВС противника;

2) «усмирительная война». Регулярные ВС против иррегулярных формирований противника;

3) «повстанческая война». Иррегулярные формирования против регулярных ВС противника;

4) «бандитская война». Иррегулярные формирования против иррегулярных формирований противника [3, с. 286].

Представленная матрица позволяет осознать место и характер каждого конкретного военного конфликта в диапазоне регулярность - иррегулярность. Из четырех типов военных конфликтов три - «усмирительная война», «повстанческая война» и «бандитская война» - являются иррегулярными. В них или с одной, или с обеих сторон применяются иррегулярные формирования. Иррегулярный характер военных конфликтов этого типа проявляется в особенностях его развития и перспективах разрешения. В таком конфликте участвует как минимум одна сторона, представленная негосударственным актором, что автоматически переводит сам военный конфликт в состояние неопределенности. Развитие такого конфликта будет проходить с высокой долей вероятности по пути «войны без правил» [3, с. 321].

«Регуляры» вынуждены учитывать и подстраиваться под действия «иррегуляров», а те стремятся, как правило, избегать прямых столкновений с регулярными войсками противной стороны, действуя по принципу «ударил - беги».

Логика иррегулярной войны вынуждает даже регулярные войска, в конечном счете, перейти к тактике «иррегуляров» и перевести конфликт в форму бандитской войны. Сторона, применяющая в войне регулярные ВС, формирует в этих условиях свои иррегулярные силы.

Анализ приведенной матрицы военных конфликтов показывает, что из четырех типов военных конфликтов два являются симметричными (традиционная и бандитская война) и два асимметричными (усмирительная и повстанческая война).

В широком смысле асимметричный конфликт предполагает столкновение между сильной в материальном и ином отношении стороной и слабой стороной. Асимметричность предполагает имманентно присущее и принципиально неустранимое качественное (а не количественное!) неравенство сторон в силах, средствах, возможностях [3, с. 322].

Асимметричный конфликт изначально неравен и неравноправен, сильная сторона обладает безусловным преимуществом, которое создает объективные условия для достижения победы. Но довольно часто сильная сторона оказывается абсолютно уверенной в своей силе, теряет способность адекватно оценивать обстановку, прогнозировать и отражать возможные угрозы, полностью успокаивается и утрачивает бдительность.

Важным условием эффективного использования непрямой стратегии слабой стороной является ее поддержка большинством или значительной частью активных групп населения, проживающего на территории конфликта [4, с. 180]. Каково принципиальное отличие между симметричными и асимметричными военными конфликтами? 
В первом случае однотипные формирования сил противоборствующих сторон однотипно действуют друг против друга. В случае бандитской войны, которая тоже является вариантом симметричной войны, «иррегуляры» с обеих сторон действуют по своему усмотрению без оглядки на требования воинских уставов и наставлений по ведению военных действий.

Во втором случае - варианты усмирительной и повстанческой войны - разнотипные противники применяют разную тактику, разные формы и способы действий.

Асимметричным конфликтом можно считать мятежевойну, концепцию которой сформулировал представитель российского Генштаба полковник Е. Э. Месснер, а также контрпартизанские, контрповстанческие, контртеррористические действия и операции.

В понятие асимметричного конфликта вписывается популярная на Западе концепция войны четвертого поколения, которая три десятилетия активно разрабатывается американскими военными экспертами.

Стоит обратить внимание на перспективы развития теории военного конфликта.

В прежние эпохи в войнах важным считалось завоевание территории, ресурсов побежденной стороны. В перспективе важнейшим будет считаться подчинение воли противника своей в интересах собственного развития. В перспективной войне воевать будут на всей поверхности территорий противостоящих государств, во всех сферах человеческого бытия с использованием всего арсенала противоборства.

Как отмечал Е. Э. Месснер, война будет идти в четырехмерном пространстве, так как психика воюющих народов является четвертым измерением военного конфликта. Вполне закономерно, что автор мятежевойны определил следующую иерархию целей: 1) развал морали вражеского народа; 2) разгром его активной части (воинства, партизанства, борющихся народных движений); 3) захват или уничтожение объектов психологической ценности; 4) захват или уничтожение объектов материальной ценности; 5) эффекты внешнего порядка ради приобретения новых союзников, потрясения духа союзников врага [3, с. 330].

Одним из подходов к оценке сущности и характера асимметричной войны является концепция войны четвертого поколения, разработанная в США. Суть подхода американских военных экспертов можно выразить следующими тезисами. «Поле боя для войны четвертого поколения - все общество противника целиком. Понятие стратегического тыла как таковое перестает существовать. Зависимость боевых подразделений от тылового обеспечения будет крайне незначительной. Массирование живой силы и огня утратит свое значение и даже, более того, может стать недостатком. Целью войны станет «сокрушение противника внутренне», а не его физическое уничтожение.

Различие между войной и миром будет расплывчатым, если вообще будет. Важные военные объекты (аэродромы, узлы связи, штабы), равно как и их «гражданские» аналоги - правительственные сооружения, заводы, промышленные объекты - станут редкими явлениями ввиду их уязвимости.

В то же время новая технология несет с собой и недостатки - появляются новые уязвимые места, которые ранее отсутствовали.

Военные действия будущего будут представлять собой действия небольших групп высокопрофессиональных солдат. Целями для таких групп будут скорее объекты гражданского сектора, чем военного. Понятия фронта и тыла в войне будущего будут отсутствовать. Им на смену придут понятия «объект - цель» и «объект не цель». Боевые части будут обладать разведывательными и ударными функциями.

Понятия тактики и стратегии смешаются. Одной из самых сложных задач для командиров всех степеней станет выбор целей на условном поле боя, при этом основными критериями будет политическая и культурная значимость целей, а не их сугубо военное значение.

Психологические операции приобретут доминирующее значение на оперативном и стратегическом уровнях. «Телевизионные новости могут стать более мощным оружием, чем бронетанковые дивизии» [3, с. 332-334].

По мнению А. И. Владимирова, можно выделить следующие направления изменений: размывание грани между комбатантами и некомбатантами; основное поле и театр войны - национальное сознание и национальная культура; основной формой войны, возникающей на основе идеологии, является массовый терроризм [5, с. 399].

Возвращаясь к матрице военных конфликтов, систематизировавшей типы войн и вооруженных конфликтов в зависимости от типа применяемых сил и средств, можно сделать вывод, что современные военные конфликты имеют комбинированный характер с преобладанием тех или иных характеристик, что и позволяет их условно относить к одному из четырех типов [3, с. 336].

Как отмечалось, традиционные войны стали рудиментарными. В составе регулярных ВС современных государств имеются полувоенные формирования, которые в своих действиях тайно или явно используют приемы и способы действий иррегулярных формирований.

Главными побудительными мотивами скатывания в состояние иррегулярной войны 
являются: возрастание числа иррегулярных формирований у противника; невозможность достижения военных и политических целей боя, сражения, военной кампании или войны только силами регулярных войск; необходимость скрыть определенные свои действия, акции или операции от общественного внимания и др. В ситуации повстанческой войны иррегулярные формирования могут оказаться перед необходимостью удерживать район местности или организовать оборону важного объекта. «Иррегуляры» вынуждены будут перейти к «правильным» действиям, тактике регулярных войск. В результате тип реальной войны или вооруженного конфликта становится все менее четко различимым. Конфликты разных типов эволюционируют в «пограничную зону», в которой они при сохранении доминирования характеристик своего типа приобретают некоторые черты конфликтов другого типа.

Сторона, стремящаяся к установлению или сохранению своей государственности, будет ориентироваться на регулярные принципы формирования своих сил и регулярную тактику действий. Что же касается оппозиционных сил, то они, естественно, с большей вероятностью тяготеют к привычной тактике иррегулярности. Однако если оппозиция стремится к завоеванию государственности, она вынуждена перестраиваться на регулярные принципы комплектования своих сил и тактику действий. Таким образом, регулярные силы и есть тот самый инструмент насилия в руках государства, который только и способен гарантировать его существование и защиту.

Если же внутренняя оппозиция не ориентируется на формирование государственности, то иррегулярная война может длиться бесконечно долго: непрофессионалам легче воевать в составе банд. Опыт войн и вооруженных конфликтов последних лет позволяет предположить, что вероятный военный конфликт будущего будет лежать именно в «пограничной зоне» предложенной И. М. Поповым и М. М. Хамзатовым матрицы и представлять собой сложную комбинацию из действий регулярных и иррегулярных сил всех противоборствующих сторон. Важнейшей характеристикой военных конфликтов из «пограничной зоны» матрицы является высокая степень хаотизации. Регулярные ВС тяготеют к максимальной структурной иерархичности и структурированности; иррегулярные формирования, напротив, основаны на организационной аморфности.

Таким образом, все военные конфликты будут носить сложный регулярно-иррегулярный характер. В связи с этим возможны два варианта: регулярные ВС и формы военных действий превалируют над иррегулярными или иррегулярные формирования и формы военных действий превалируют над регулярными.
Сегодня все чаще употребляется термин «гибридная война». Изначально под термином понимались новые нетрадиционные опасности и угрозы для национальной безопасности государства. Затем этот подход был применен для передачи сущности военного конфликта, в котором регулярным войскам противостояли противники иррегулярного типа.

В работе американского профессора Ф. Хоффмана «Гибридная война и ее вызовы» отмечается: «Мы сталкиваемся с конвергенцией вооруженных сил и общества, либо государственных и негосударственных организаций, и тех способностей, которыми они обладают. И конечно, огромное значение обрели изменившиеся, конвергентные способы ведения войны» [4, с. 183]. «Национальная военная стратегия» США определила еще в 2015 г. роль и место гибридных войн в общей системе регулярных и иррегулярных военных конфликтов и дала всем им соответствующие определения.

Государственный конфликт: для разгрома врага задействуются крупные группировки ВС и самые современные военные технологии во всех сферах.

Гибридный конфликт: сочетается использование обычных регулярных и иррегулярных сил для создания эффекта неоднозначности, захвата инициативы и парализации врага.

Негосударственный конфликт: задействуются подразделения и сети для подрыва позиций правительства и получения контроля над населением [3, с. 343].

Ф. Хоффман утверждает, что «в ходе гибридной войны могут вестись и обычные боевые действия, партизанская тактика и подразделения, террористические акты, криминальное насилие и принуждение» [4, с. 185].

Гибридным конфликтом можно назвать военный конфликт, который ведется иррегулярными силами, смешанными с регулярными войсками, и характеризуется одновременным применением иррегулярной и регулярной стратегии и тактики действий [3, с. 344].

Транснациональные и национальные криминальные структуры сегодня активно проявляют себя в качестве реального «действующего лица» современных военных конфликтов.

Таким образом, еще раз обратим внимание, что иррегулярный военный конфликт неизбежно тяготеет к «войне без правил», т. е. к игнорированию законов и обычаев войны.

Заключение. Итак, решение теоретических проблем, связанных с войнами будущего составляет серьезную научную задачу, новое поле для профессионального образования как гражданских, так и военных управленцев. Наша задача - не допустить разрыва между пониманием природы и сущности современной войны, знанием ее типов, 
способов, принципов ведения и практикой подготовки войск. Наиболее характерной особенностью современных военных конфликтов остается комбинированная или размытая природа противоборства.

Анализ западных подходов к противоборству показывает, что традиционным является соединение трех терминов - агрессия, война и воля. В англо-саксонской традиции война не обязательно связана с применением летального оружия. Западные стратеги следуют за классиком военной мысли К. Клаузевицем, утверждавшим: «Война это акт насилия, имеющий целью заставить противника выполнить нашу волю» [6, с. 35]. Кроме того, американские специалисты все чаще уходят от термина «война», заменяя его такими понятиями, как «конфликт», «противоборство», «противостояние» и т. п. Фактически появилось новое состояние социума - «мировойна», «войномир» [4, с. 408].

Как сказал один из сотрудников Пентагона: «Задача теперь состоит не в уничтожении живой силы, но в подрыве целей, взглядов и мировоззрения населения, в разрушении социума» [5, с. 474].

В силу того, что мир становится более насильственным и военизированным, теория и практика управления социумом и государством на всех уровнях объективно требует дальнейшей разработки и понимания философии борьбы (войны), поскольку она является методологической основой обеспечения безопасности управляемых объектов.

\section{Список литературы}

1. Ксенофонтов В. А. Война, национальная безопасность, гражданско-военные отношения, гуманитарное знание: взаимосвязь явлений и перспективы их развития // Гуманитарные проблемы военного дела. 2015. № 4 (5). С. 17-27.

2. Военная доктрина Республики Беларусь: утв. Законом Респ. Беларусь 20.07.2016 г., № 412-3. URL: https://www.pravo.by (дата обращения: 11.01.2021).

3. Попов И. М., Хамзатов М. М. Война будущего: концептуальные основы и практические выводы. Очерки стратегической мысли. М.: Кучково поле, 2016. 832 с.

4. Ларина Е. С., Овчинский В. С. Мировойна. Все против всех. Новейшие концепции боевых действий англосаксов. Составление, введение, заключение. М.: Книжный мир, 2015. 456 с.

5. Владимиров А. И. Основы общей теории войны: монография: в 2 ч. Часть I: Основы теории войны. М.: Моск. фин.-пром. ун-т «Синергия», 2013. 832 с. 2019.

6. Клаузевиц К. О войне; пер. с нем. М.: Логос: Наука, 448 с.

\section{References}

1. Ksenofontov V. A. War, national security, civil-military relations, humanitarian knowledge: interrelation of phenomena and prospects for their development. Gumanitarnyye problemy voyennogo dela [Humanitarian problems of military affairs], 2015, no. 4 (5), pp. 17-27 (In Russian).

2. Voyennaya doktrina Respubliki Belarus': utverzhdena Zakonom Respubliki Belarus' 20.07.2016, no. 412-Z. Available at: https://www.pravo.by (accessed 11.01.2021).

3. Popov I. M., Khamzatov M. M. Voyna budushchego: kontseptual'nyye osnovy i prakticheskiye vyvody. Ocherki strategicheskoy mysli [War of the future: conceptual foundations and practical conclusions. Essays on strategic thinking]. Moscow, Kuchkovo pole Publ., 2016, 832 p.

4. Larina E. S., Ovchinskiy V. S. Mirovoyna. Vse protiv vsekh. Noveyshiye kontseptsii boyevykh deystviy anglosaksov. Sostavleniye, vvedeniye, zaklyucheniye [All against all. The latest concepts of Anglo-Saxon warfare. Compilation, introduction, conclusion]. Moscow, Knizhnyy mir Publ., 2015. 456 p.

5. Vladimirov A. I. Osnovy obshchey teorii voyny: $v 2$ chastyakh. Chast' I: Osnovy teorii voyny [Fundamentals of the General theory of war: in 2 parts. Part I: Fundamentals of the theory of war]. Moscow, Moskovskiy finansovo-promyshlennyy universitet "Sinergiya" Publ., 2013. $832 \mathrm{p}$

6. Clausewitz K. O voyne [About war]. Moscow, Logos Publ., Nauka Publ., 2019. 448 p.

\section{Информация об авторе}

Ксенофонтов Владислав Анатольевич - кандидат философских наук, доцент, профессор кафедры идеологической работы и социальных наук. Военная академия Республики Беларусь (220057, г. Минск, пр-т Независимости, 220, Республика Беларусь). E-mail: nksena777@gmail.com

\section{Information about the author}

Ksenofontov Vladislav Anatol'yevich - PhD (Philosophy), Associate Professor, Professor, the Department of Ideological Work and Social Sciences. Military Academy of the Republic of Belarus (220, Nezavisimosti Ave., 220057, Minsk, Republic of Belarus). E-mail: nksena777@gmail.com 